\title{
The relationship between human leukocyte antigen-DP/DQ gene polymorphisms and the outcomes of HCV infection in a Chinese population
}

Peng Huang ${ }^{1,2+}$, Haozhi Fan ${ }^{1+}$, Ting Tian ${ }^{1}$, Peiwen Liao ${ }^{3}$, Jun $\mathrm{Li}^{4}$, Rongbin $\mathrm{Yu}^{1}$, Xueshan Xia ${ }^{5}$, Yue Feng ${ }^{5}$, Jie Wang ${ }^{6}$, Yuan Liu', Yun Zhang ${ }^{1,2}$ and Ming Yue ${ }^{4^{*}}$ (i)

\begin{abstract}
Background: Recently, human leukocyte antigen (HLA) class-II gene polymorphisms have been reported to be related to Hepatitis $\mathrm{C}$ virus (HCV) infection and chronicity. The objective of this study was to explore the relationship of HLA-DP rs9277535 and HLA-DQ rs7453920 with the outcomes of HCV infection.

Methods: The rs9277535 and rs7453920 were genotyped in 370 subjects with chronic HCV infection, 194 subjects with spontaneous HCV clearance, and 973 subjects with non-HCV infection from the Chinese population using the ABI TaqMan allelic discrimination assay.

Results: Logistic regression analyses showed that the minor allele A of rs7453920 significantly increased the susceptibility of HCV infection in dominant model (adjusted $\mathrm{OR}=1.33,95 \% \mathrm{Cl}: 1.04-1.71, P=0.026$ ) and additive models (adjusted $\mathrm{OR}=1.30,95 \% \mathrm{Cl}: 1.06-1.60, P=0.012$ ). Rs9277535 A allele significantly increased the risk of chronic HCV infection in dominant model (adjusted $\mathrm{OR}=1.52,95 \% \mathrm{Cl}: 1.01-2.28, P=0.046$ ). Haplotype AA showed a higher risk of HCV infection than the most frequent haplotype $\mathrm{GG}$ (adjusted $\mathrm{OR}=1.37,95 \% \mathrm{Cl}$ : 1.05-1.78, $P=0.018$ ).
\end{abstract}

Conclusion: The HLA-DQ rs7453920 and -DP rs9277535 mutations were significantly associated with HCV infection susceptibility and chronicity, respectively.

Keywords: Hepatitis C virus, HLA, Gene polymorphism, Drug use, Hemodialysis, Paid blood donors

\section{Background}

Hepatitis $\mathrm{C}$ virus (HCV) infection remains a major public health concern, although there has been significant progress in the treatment of $\mathrm{HCV}$ infection due to the presence of direct antiviral drugs (DAAs). Based on the estimation of the World Health Organization (WHO), there are 130-150 million people infected with HCV globally, and about $30 \%$ of infected people will be spontaneously clear, while the others will develop chronic infection, and further progress to cirrhosis and hepatocellular carcinoma (HCC) [1]. In China, the

\footnotetext{
*Correspondence: njym08@163.com

${ }^{\dagger}$ Equal contributors

${ }^{4}$ Department of Infectious Diseases, the First Affiliated Hospital of Nanjing Medical University, Nanjing 210029, China

Full list of author information is available at the end of the article
}

average prevalence of $\mathrm{HCV}$ infection is about $3.2 \%$, a total of about 29 million hepatitis $C$ virus carriers [1]. The pathogenesis of $\mathrm{HCV}$ infection and chronicity are elusive, but biological characteristics of $\mathrm{HCV}$, host immunity, genetic background and environmental behavior factors are deemed to be interactively involved with the complex pathogenesis [2-4].

The innate and adaptive immune response after the infection of $\mathrm{HCV}$, which varies across individuals, affect the susceptibility and chronicity to HCV infection $[5,6]$. The human leukocyte antigen (HLA) system, as the major histocompatibility complex (MHC) in human, plays an important role in specific immune response and immune regulation through the interaction with natural killer (NK) cells, T- and B- lymphocytes and cytokines [7, 8]. HLA molecules are categorized into three basic groups: class I, 
class II, and class III, which genes are located close together on the short arm of chromosome 6 [9].

It is globally recognized that HLA class II molecules, categorized into three sub-regions: $H L A-D R,-D Q$ and $-D P$, are key determinants in the immune response to $\mathrm{HCV}$ infection through the effective presentation of $\mathrm{T}$ cells to viral antigens $[10,11]$. Researchers have recently discovered that variation in $H L A$ class II genes are determinants of the susceptibility and chronicity of HCV infection. For example, a comparative review showed that $H L A D R * 13$ alleles were protective against $\mathrm{HCV}$ infections in several populations [12]. Katayoun et al. conducted a genome wide association study (GWAS) and found the $H L A-D R B 1 * 0301$ alleles were significantly associated with viral clearance, and $D Q A 1 * 0201$ and $D Q B 1 * 0602$ alleles are significantly associated with HCV persistence [13].

It has been studied that the single nucleotide polymorphism (SNP) rs9277535 of HLA-DP is associated with systemic lupus erythematosus (SLE) susceptibility, cervical cancer susceptibility, and persistent hepatitis B virus (HBV) infection, the SNP rs7453920 of $H L A-D Q$ is also suggested to be associated with ankylosing spondylitis (AS) susceptibility, persistent HBV infection [14-19]. However, the evidence is sparse about whether above two SNPs is related to HCV in a Chinese population. Therefore, we investigate the relationship of the HLA$D P$ rs9277535 and $-D Q$ rs7453920 with the susceptibility and chronicity of $\mathrm{HCV}$ infection in the Chinese population.

\section{Methods}

\section{Participants}

A total of 437 consecutive participants of drug users were recruited from the Nanjing compulsory drug rehabilitation center (Nanjing, Jiangsu, China) between May 2006 and Dec 2009, 714 consecutive participants of hemodialysis (HD) were recruited from nine hospital hemodialysis centers in southern China between Nov 2008 and Dec 2009, and 386 consecutive participants of paid blood donors (PBD) were recruited from Danyang (Danyang, Jiangsu, China) in Apr 2011, respectively. Cases would be excluded if they were affected or lived with any other hepatotropic virus or human immunodeficiency virus (HIV) co-infection, any other types of liver diseases (autoimmune hepatitis, metabolic disorder, alcohol liver and drugs-induced liver injury), or previous interferon and/or ribavirin therapy. All participants were grouped as follows: (1) Group A: 370 subjects with chronic HCV infection, who were anti-HCV antibodies seropositive and HCV-RNA seropositive, (2) Group B: 194 subjects with spontaneous HCV clearance, who were anti-HCV antibodies seropositive and HCV-RNA seronegative, and (3) Group C: 973 subjects with non-HCV infection, who were anti-HCV antibodies seronegative and HCV-RNA seronegative. All patients were diagnosed by experienced physicians based on clinical interviews, laboratory results and international standards. Structured interviews and standardized questionnaires were utilized to collect demographic and environmental exposure history information. Blood samples $(\sim 5 \mathrm{~mL})$ were then collected for further virus detection, serological testing, and host DNA genotyping.

Each participates was recruited prior informed consent, agreed to participate in this study and sample collection. The study followed the Helsinki Declaration and was approved by the Institutional Review Board of Nanjing Medical University (Nanjing, China).

\section{Serological testing}

The serological status of anti-HCV antibodies of the subjects was detected by the third-generation enzymelinked immunosorbent assay (ELISA) (Architect AntiHCV assay, Abbott Laboratories, Abbott Park, IL, USA). HCV RNA was extracted from plasma using kit (Cobas TaqMan HCV Test, Roche Diagnostics, Manheim, Germany) and HCV genotyping was performed by the Murex HCV serotype ELISA kit (Abbott, Wiesbaden, Germany). All tests were conducted in accordance with the manufacturer's instructions.

\section{Genotyping assays}

Genomic DNA was extracted from peripheral blood samples by protease $\mathrm{K}$ digestion, phenol-chloroform extraction and ethanol precipitation, and the DNA concentration was tested on NanoDrop 2000 spectrophotometer (Thermo Scientific, DE). According to the relevant HLA class II single nucleotide polymorphism (SNP) literature, two SNPs were selected as candidate sites, including HLA-DP: rs9277535 and $H L A-D Q$ : rs7453920, which showed minor allele frequency $(\mathrm{MAF})>5 \%$ in Chinese Han population in NCBI dbSNP database (http://www.ncbi.nlm.nih.gov/SNP). SNP rs9277535 and rs7453920 were genotyped using the TaqMan allele identification assay on the ABI PRISM 7900HT system (Applied Biosystems, Foster City, CA, USA). Rs9277535 and rs7453920 specific TaqMan probes, forward and reverse primer information is shown in Additional file 1: Table S1. All genotyping was performed blindly in the context that the operator did not know the clinical data of the subject. All genotyping assays were conducted with blinded to the subject's clinical data. In each of the 384-well plates, two blank controls (water) were used for quality control, and randomly selected $10 \%$ of the samples were submitted to repeated experiments, each SNP yield 100\% consistency. The success rates of the two SNP genotypes were above $94 \%$. 


\section{Statistical analysis}

The distributions of demographic and clinical data between groups were obtained by the one-way ANOVA (for variance homogeneity) or Welch (for variance) and chi-square (X2) test. Hardy-Weinberg equilibrium (HWE) was assessed in three groups by a goodness-of-fit $\mathrm{X}^{2}$ tests. The odds ratio (OR) and 95\% confidence interval $(\mathrm{CI})$ were calculated to estimate the natural susceptibility and long-term risk of SNP and HCV infection by binary logistic regression analysis, with adjusting for age, sex, high-risk population, alanine aminotransferase (ALT), aspartate aminotransferase (AST), and HCV genotypes. The corresponding OR and their $95 \% \mathrm{CI}$ were calculated using the co-dominant model, the dominant model and the additive model, respectively. The parameters $\mathrm{D}^{\prime}$ and $\mathrm{R}^{2}$ were calculated using the Haploview software (version 4.2) to analyze whether the two studied SNP linkage disequilibrium (LD). Single haplotype analysis was performed utilizing PHASE software (version 2.1) based on the observed genotype. All statistical analyses were performed using stata13.0. $P<0.05$ in a twosided test was considered statistically significant.

\section{Results}

\section{Demographic and clinical characteristics}

The demographic and clinical characteristics of the 370 subjects with chronic HCV infection, 194 subjects with spontaneous HCV clearance, and 973 subjects with non-
HCV infection were set out in Table 1. Distributions of age and gender were comparable among the three groups $(P=$ 0.090 and 0.860 , respectively). However, there were significantly different distributions of ALT, AST, high-risk population, and HCV genotypes in the three groups (all $P<0.001$ ).

Observed genotype frequencies for rs9277535 and rs7453920 in non-HCV infection group were all in Hardy-Weinberg equilibrium $(P=0.107$ for rs9277535, $P=0.114$ for rs9277535, respectively).

\section{Association of candidate SNPs with HCV susceptibility and chronicity}

Compared with the spontaneous $\mathrm{HCV}$ clearance group (group B), logistic regression analysis showed that the minor allele A of HLA-DP rs9277535 significantly increased the risk of chronic $\mathrm{HCV}$ infection in dominant model (adjusted OR $=1.52$, 95\% CI: $1.01-2.28, P=0.046$ ), after adjusting for gender, age, ALT, AST, high-risk population, and HCV genotypes (Table 2).

Compared with the non-HCV infection group, logistic regression analysis showed that the minor allele $\mathrm{A}$ of HLA-DQ rs7453920 significantly increased the susceptibility of $\mathrm{HCV}$ infection in dominant model (adjusted $\mathrm{OR}=1.33,95 \% \mathrm{CI}: 1.04-1.71, \mathrm{P}=0.026)$ and additive model (adjusted OR $=1.30,95 \%$ CI: $1.06-1.60, \quad P=$ 0.012), adjusted by gender, age, ALT, AST, and high-risk population. But there was no evidence that there was a

Table 1 Demographic and clinical characteristics in subjects

\begin{tabular}{|c|c|c|c|c|}
\hline \multirow[t]{2}{*}{ Variables } & \multirow{2}{*}{$\begin{array}{l}\text { Group A (\%) } \\
n=370\end{array}$} & \multirow{2}{*}{$\begin{array}{l}\text { Group B (\%) } \\
n=194\end{array}$} & \multirow{2}{*}{$\begin{array}{l}\text { Group C (\%) } \\
n=973\end{array}$} & \multirow[t]{2}{*}{$P$} \\
\hline & & & & \\
\hline Mean age, year (SD) & $46.86 \pm 13.05$ & $47.03 \pm 11.26$ & $48.43 \pm 13.73$ & $0.090^{\mathrm{a}}$ \\
\hline Age $\geq 50(\%)$ & $157(22.6)$ & $74(10.7)$ & $463(66.7)$ & $0.026^{b}$ \\
\hline Gender & & & & $0.860^{b}$ \\
\hline Male & $204(55.1)$ & $110(56.7)$ & $531(54.6)$ & \\
\hline Female & $166(44.9)$ & $84(43.3)$ & $442(45.4)$ & \\
\hline $\mathrm{ALT} \geq 40 \mathrm{U} / \mathrm{L}$ & $104(28.1)$ & $27(13.9)$ & $48(4.9)$ & $<0.001^{c}$ \\
\hline $\mathrm{AST} \geq 40 \mathrm{U} / \mathrm{L}$ & $128(34.6)$ & $30(15.5)$ & $80(8.2)$ & $<0.001^{\mathrm{C}}$ \\
\hline High-risk population & & & & $<0.001^{b}$ \\
\hline Drug user & $155(41.9)$ & 36 (18.6) & $246(25.3)$ & \\
\hline$H D$ & $74(20.0)$ & $89(45.9)$ & $551(56.6)$ & \\
\hline PBD & $141(38.1)$ & 69 (35.6) & $176(18.1)$ & \\
\hline HCV genotypes & & & & $<0.001^{b}$ \\
\hline 1 & $236(63.8)$ & $114(58.8)$ & - & \\
\hline Non-1 & $51(13.8)$ & $53(27.3)$ & - & \\
\hline Mixed & $83(22.4)$ & 27 (13.9) & - & \\
\hline
\end{tabular}

Group A: chronic HCV infection; Group B: spontaneous HCV clearance; Group C: non-HCV infection; Non-1: genotype 2, 3 and unknown; Mixed: co-infected with genotype $1 / 2 / 3$

Abbreviations: ALT, alanine transaminase; AST, aspartate transaminase; SD, standard deviation; HD, hemodialysis patient; PBD, paid blood donors

${ }^{a} P$ value of Welch among three groups, heterogeneity of variance

${ }^{b} P$ value of $X^{2}$-test among three/two groups

${ }^{c} P$ value of Kruskal-Wallis test or Mann-Whitney $U$ test among three/two groups 
Table 2 Association of HLA-DP/DQ with HCV susceptibility and clearance

\begin{tabular}{|c|c|c|c|c|c|c|c|}
\hline \multirow[t]{2}{*}{ SNPs (genotype) } & \multirow{2}{*}{$\begin{array}{l}\text { Group A } \\
\text { n (\%) }\end{array}$} & \multirow{2}{*}{$\begin{array}{l}\text { Group B } \\
\mathrm{n}(\%)\end{array}$} & \multirow{2}{*}{$\begin{array}{l}\text { Group C } \\
\text { n (\%) }\end{array}$} & \multicolumn{2}{|c|}{ Group $(A+B) /$ Group C } & \multicolumn{2}{|l|}{ Group A/Group B } \\
\hline & & & & $\mathrm{OR}^{\mathrm{a}}$ & $P^{a}$ & $\mathrm{OR}^{\mathrm{b}}$ & $p^{\mathrm{b}}$ \\
\hline \multicolumn{8}{|l|}{ HLA-DP rs9277535 } \\
\hline GG & $96(26.1)$ & $64(33.2)$ & $276(28.7)$ & 1.00 & - & 1.00 & - \\
\hline$A G$ & $190(51.6)$ & $83(43.0)$ & $455(47.3)$ & $1.02(0.79-1.33)$ & 0.876 & $1.60(1.03-2.48)$ & 0.035 \\
\hline AA & $82(22.3)$ & $46(23.8)$ & $231(24.0)$ & $1.00(0.73-1.37)$ & 0.989 & $1.35(0.81-2.27)$ & 0.250 \\
\hline Dominant model & & & & $1.01(0.79-1.30)$ & 0.906 & $1.52(1.01-2.28)$ & 0.046 \\
\hline Additive model & & & & $1.00(0.86-1.17)$ & 0.979 & $1.19(0.91-1.54)$ & 0.198 \\
\hline \multicolumn{8}{|l|}{ HLA-DQ rs7453920 } \\
\hline GG & $237(69.3)$ & $119(66.1)$ & $671(72.4)$ & 1.00 & - & 1.00 & - \\
\hline$A G$ & $84(24.6)$ & 55 (30.6) & $228(24.6)$ & $1.26(0.97-1.65)$ & 0.084 & $0.90(0.58-1.39)$ & 0.643 \\
\hline AA & $21(6.1)$ & $6(3.3)$ & $28(3.0)$ & $1.84(1.03-3.29)$ & 0.040 & $1.96(0.71-5.37)$ & 0.193 \\
\hline Dominant model & & & & $1.33(1.04-1.71)$ & 0.026 & $1.00(0.66-1.52)$ & 0.989 \\
\hline Additive model & & & & $1.30(1.06-1.60)$ & 0.012 & $1.10(0.78-1.54)$ & 0.599 \\
\hline
\end{tabular}

Group A: chronic HCV infection; Group B: spontaneous HCV clearance; Group C: non-HCV infection; Group (A + B): HCV-infected patients Abbreviations: SNPs single nucleotide polymorphisms

Bold type indicates statistically significant results

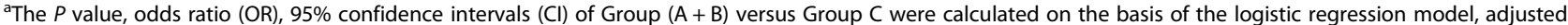
by gender, age, ALT, AST, and high-risk population

${ }^{\text {b} T h e ~} P$ value, odds ratio (OR), 95\% confidence intervals (Cl) of Group A versus Group B were calculated on the basis of the logistic regression model, adjusted by gender, age, ALT, AST, high-risk population, and HCV genotypes

significant association between HLA-DP rs9277535 variant genotype and HCV susceptibility (Table 2).

\section{Stratified analysis}

In order to control the bias due to gender, age, highrisk population, and viral genotypes in each population, we further performed the stratified analysis. The results of the stratified analysis are presented in Table 3. Dominant models were employed in stratified analysis for each SNP. Logistic regression analysis showed that rs9277535 variant genotypes significantly increased risk of chronic $\mathrm{HCV}$ infection among people less than 50 years old (adjusted $\mathrm{OR}=1.71$, 95\% CI: $1.02-2.86, \mathrm{P}=0.042$ ) and among PBD population (adjusted $\mathrm{OR}=1.94,95 \% \mathrm{CI}: 1.04-3.63, \quad P=$ 0.037). While rs7453920 variant genotypes significantly increased the susceptibility of $\mathrm{HCV}$ infection among people less than 50 years old (adjusted $\mathrm{OR}=$ 1.42, 95\% CI: $1.02-1.98, P=0.040)$ and HD population (adjusted $\mathrm{OR}=1.53,95 \% \mathrm{CI}: 1.04-2.25, \quad P=$ 0.029). However, no significant association of rs9277535 and rs7453920 variant genotypes with HCV susceptibility and chronicity was observed in other strata (all P>0.05) (Additional file 1: Table S2 and S3).

\section{Haplotype analysis}

The D' value and $R^{2}$ value were used for quantifying the level of $\mathrm{LD}$, and found no significant $\mathrm{LD}$ between rs9277535 and $\operatorname{rs} 7453920\left(D^{\prime}=0.131, R^{2}=0.004\right)$. To further evaluate the effects of HLA-DP and HLA-DQ polymorphism on HCV infection outcomes, which consisted of rs9277535 and rs7453920 variant alleles, we performed haplotype analysis (Table 4). When compared with the most frequent GG haplotype, the haplotype carrying rs3077-A and rs2856718-A (AA) showed increased the susceptibility of $\mathrm{HCV}$ infection (adjusted $\mathrm{OR}=1.37$, 95\% CI: 1.05-1.78, $P=0.018$ ).

\section{Discussion}

It is well known that HCV is a serious public health problem. Studies on the relationship between HLA Class II gene polymorphisms and the susceptibility and chronicity of $\mathrm{HCV}$ infection help us better understand the complicated mechanism. The current research found that $H L A-D P$ rs9277535 A and $-D Q$ rs7453920 A allele significantly increased the risk of $\mathrm{HCV}$ chronicity and $\mathrm{HCV}$ infection in Chinese Han population, respectively.

The HLA determinant as the principal component of immunogenicity factors has been found associated with HCV infection [20, 21]. HLA-DQ belongs to HLA Class II molecules play crucial roles in the regulation of immune responses [22]. HLA-DQ molecules, which are induced when $H L A-D Q$ genes are expressed, play a regulatory role by binding to exogenous antigens and presenting exogenous substances to $\mathrm{CD} 4+\mathrm{T}$ lymphocytes $[23,24]$. A previous study detected genetic variants of rs2856718 in intron region of $H L A-D Q$ genes also strongly associated with the susceptibility of $\mathrm{HCV}$ infection in Chinese population [25]. The current study 
Table 3 Stratified analysis the association of HLA-DP/DQ with HCV susceptibility and chronicity

\begin{tabular}{|c|c|c|c|c|c|}
\hline \multirow{2}{*}{$\overline{S N P}$} & \multirow[t]{2}{*}{ Subgroups } & \multicolumn{2}{|c|}{ Group $(A+B) /$ Group C } & \multicolumn{2}{|l|}{ Group A/Group B } \\
\hline & & $\overline{\mathrm{OR}^{\mathrm{a}}}$ & $P^{a}$ & $\overline{\mathrm{OR}^{\mathrm{b}}}$ & $P^{b}$ \\
\hline \multirow[t]{7}{*}{ rs9277535 } & Age & & & & \\
\hline & $<50$ & $1.02(0.74-1.42)$ & 0.901 & $1.71(1.02-2.86)$ & 0.042 \\
\hline & $\geq 50$ & $1.01(0.69-1.47)$ & 0.965 & $1.29(0.64-2.57)$ & 0.475 \\
\hline & High-risk pop & & & & \\
\hline & Drug user & $0.92(0.58-1.47)$ & 0.733 & $2.19(0.94-5.11)$ & 0.069 \\
\hline & $\mathrm{HD}$ & $1.35(0.89-2.04)$ & 0.162 & $0.87(0.42-1.81)$ & 0.700 \\
\hline & PBD & $0.93(0.60-1.45)$ & 0.746 & $1.94(1.04-3.63)$ & 0.037 \\
\hline \multirow[t]{7}{*}{ rs7453920 } & Age & & & & \\
\hline & $<50$ & $1.42(1.02-1.98)$ & 0.040 & $0.82(0.49-1.37)$ & 0.445 \\
\hline & $\geq 50$ & $1.21(0.82-1.78)$ & 0.329 & $1.23(0.58-2.58)$ & 0.591 \\
\hline & High-risk pop & & & & \\
\hline & Drug user & $1.36(0.83-2.22)$ & 0.218 & $1.22(0.45-3.32)$ & 0.693 \\
\hline & $\mathrm{HD}$ & $1.53(1.04-2.25)$ & 0.029 & $1.02(0.51-2.01)$ & 0.962 \\
\hline & PBD & $1.20(0.75-1.93)$ & 0.449 & $0.83(0.43-1.60)$ & 0.572 \\
\hline
\end{tabular}

Group A: chronic HCV infection; Group B: spontaneous HCV clearance; Group C: non-HCV infection; Group (A + B): HCV-infected patients

Abbreviations: HD, hemodialysis patient; PBD, paid blood donors

Bold type indicates statistically significant results

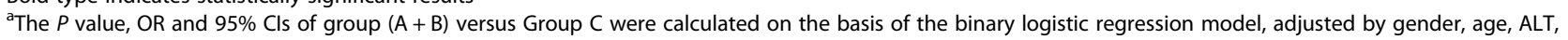
AST, and high-risk population in dominant model (GG versus AG + AA for rs9277535 and rs7453920)

${ }^{\mathrm{b}}$ The $P$ value, OR and $95 \% \mathrm{Cls}$ of group A versus Group B were calculated on the basis of the binary logistic regression model, adjusted by gender, age, ALT, AST, high-risk population, and HCV genotypes in dominant model (GG versus AG + AA for rs9277535 and rs7453920)

found that the individuals carrying $H L A-D Q$ rs7453920 A allele had a statistically significantly higher risk of $\mathrm{HCV}$ infection. It is possible that rs7453920 variation may alter the expression of the $H L A-D Q$ gene with alternation of non-coding RNA sequences, further affecting the recognition and presentation of exogenous antigen peptide, thus leading to effects on the secretion of cytokines and the differentiation of T-cells. The study of Xu et al. showed that the rs7453920G allele was a risk factor for HBV infection, while rs7453920A allele served as a protective factor in chronic Hepatitis C [26]. Furthermore, rs7453920A allele could predict the better prognosis in liver transplant recipients, and was associated with decreased risk of ankylosing spondylitis (AS) [27]. The explanation of this could be that HBV and HCV have remarkable differences in the molecular virology and specific immune responses, although both of them are hepatotrophic factors and tend to produce liver diseases. For instance, HLA DQB1*0301and HLA DRB1*11 play a protective role in $\mathrm{HCV}$ infections, but the opposite in persistent $\mathrm{HBV}$ infection [12].

Previous research has shown that low viral diversity and strong CD4+ T-cell response targeting a broad range of virus antigenic epitopes are connection with spontaneous viral clearance (SVC), while infectious agents can lead to incompetent T-cell response and

Table 4 Haplotypes analysis of rs9277535 and rs7453920 with different HCV outcomes

\begin{tabular}{|c|c|c|c|c|c|c|c|}
\hline \multirow[t]{2}{*}{ Haplotype $^{a}$} & \multirow{2}{*}{$\begin{array}{l}\text { Group A(\%) } \\
n=740\end{array}$} & \multirow{2}{*}{$\begin{array}{l}\text { Group B(\%) } \\
n=388\end{array}$} & \multirow{2}{*}{$\begin{array}{l}\text { Group C(\%) } \\
n=1946\end{array}$} & \multicolumn{2}{|c|}{ Group $(A+B) /$ Group C } & \multicolumn{2}{|c|}{ Group A/Group B } \\
\hline & & & & $\mathrm{OR}^{\mathrm{b}}$ & $p^{b}$ & $\mathrm{OR}^{\mathrm{C}}$ & $p^{c}$ \\
\hline GG & $345(46.6)$ & $191(49.2)$ & $929(47.7)$ & 1.00 & 1.00 & 1.00 & 1.00 \\
\hline GA & $39(5.3)$ & $21(5.4)$ & $92(4.7)$ & $1.07(0.74-1.54)$ & 0.712 & $0.86(0.48-1.56)$ & 0.628 \\
\hline AG & $269(36.4)$ & $130(33.5)$ & $733(36.7)$ & $0.93(0.78-1.10)$ & 0.390 & $1.18(0.88-1.58)$ & 0.278 \\
\hline AA & $87(11.8)$ & $46(11.9)$ & $192(9.9)$ & $1.37(1.05-1.78)$ & 0.018 & $1.09(0.71-1.66)$ & 0.698 \\
\hline
\end{tabular}

Group A: chronic HCV infection; Group B: spontaneous HCV clearance; Group C: non-HCV infection; Group (A + B): HCV-infected patients Abbreviations: SNPs single nucleotide polymorphisms

Bold type indicates statistically significant results

${ }^{a}$ Order of single nucleotide polymorphisms comprising the HLA class II haplotypes: s9277535 and rs7453920

${ }^{\mathrm{b}}$ The $P$ value, OR and $95 \% \mathrm{Cls}$ of group $(\mathrm{A}+\mathrm{B})$ versus Group $\mathrm{C}$ were calculated on the basis of the binary logistic regression model, adjusted by gender, age, ALT, AST, and high-risk population

'The $P$ value, OR and $95 \%$ Cls of group A versus Group B were calculated on the basis of the binary logistic regression model, adjusted by gender, age, ALT, AST, high-risk population, and HCV genotypes 
persistent infection through a variety of complex mechanisms [28]. Furthermore, the epitopes of CD4+ T-cell are highly promiscuous and can often be restricted by a variety of different HLA class II molecules [29]. Genetic association studies showed that HLA class II-restricted epitopes goes unrecognized by T-cells may be one of the possible mechanisms of $\mathrm{HCV}$ to avoid immune clearance [30]. A meta-analysis confirmed that $D Q B 1 * 02$, $D Q B 1 * 03, D R B 1 * 04$ and $D R B 1 * 11$ were associated with spontaneous hepatitis $C$ virus clearance [31]. The current study revealed that the individuals carrying HLA-DP rs9277535 A allele had a statistically significantly higher risk of chronic HCV infection. Previous research has shown that HLA-DP rs9277535A allele might protect against chronic HBV infection in Japanese, Korean, Taiwanese, and Thai populations, but might increase the risk of chronic HBV infection in Han Chinese and Saudi Arabian populations [32]. Other studies have found rs9277535A allele that could decrease SLE susceptibility, however, was associated with increased cervical cancer susceptibility in Chinese females [17, 18]. Rs9277535 may be the binding site of some microRNA (miRNA), where 3'-UTR region of HLA-DPB1 gene is found. Research indicates that miRNA affects the stability and translation of messenger RNA (mRNA) by basepairing with complementary sequences within mRNA molecules [33]. Thus, rs9277535 may affect the regulatory function of miRNA by disrupting microRNAmRNA interaction, resulting in the deregulation of the expression and stability of HLA mRNA.

The study indicated that the association between $H L A-D P / D Q$ and the susceptibility and chronicity of HCV infection was likely to be more pronounced among people less than 50 years old, PBD population and HD population. It was indicated in the previous research that chronic HD patients were with renal failure and compromised immune systems, and were less likely to clear HCV and other infection [34-36]. Therefore, we can deduce that HD patients carrying HLA-DP rs7453920 A allele were more prone to gain the genetic benefit because of severe alterations in immune systems. The current research also suggested that the haplotype AA showed a higher risk of $\mathrm{HCV}$ infection than the most frequent haplotype GG, which was consistent with the rs7453920 effect but failed to show in rs9277535 effect. This indicates that the effects of $H L A-D P$ and $H L A-D Q$ may not be independent, which has been proposed in a recent study [37]. Therefore, further fine mapping studies are recommended.

The studies generate the genetic evidence of association between HLA Class II gene polymorphisms and the outcome of $\mathrm{HCV}$ infection, which may facilitate scientists and clinicians to identify new targets for therapy and personalized medical-based strategy along with other SNP information. There are some limitations in this study. First, the participants of this study were drug addicts, HD and PBD, which have impaired immune function and thus may not represent all subjects with $\mathrm{HCV}$ persistent infection and spontaneous clearance in the general population. Second, the clinical information including the infection time of $\mathrm{HCV}$ and immunization status for each individual was not sufficient, demonstrating potential biases arising from unmeasured confounding variables. Finally, the sample size of HCV persistent infection group $(n=370)$ and spontaneous clearance group $(n=194)$ were relatively small, further research on a large scale is therefore necessary.

\section{Conclusions}

In conclusion, this study found that HLA-DQ rs7453920 A allele may be a genetic factor of $\mathrm{HCV}$ infection, while HLA-DP rs9277535 A allele may be for chronic HCV infection in the Chinese Han population.

\section{Additional file}

Additional file 1: Table S1. Information of primers and probes for TaqMan allelic discrimination. Table S2. Stratified analysis the association of HLA-DP rs9277535 with HCV clearance. Table S3. Stratified analysis the association of HLA-DQ rs7453920 with HCV susceptibility. (DOCX 32 kb)

\section{Abbreviations}

ALT: Alanine aminotransferase; AS: Ankylosing spondylitis; AST: Aspartate aminotransferase; Cl: Confidence interval; DAAs: Direct antiviral drugs; DCs: Dendritic cells; ELISA: Third-generation enzyme-linked immunosorbent assay; HCC: Hepatocellular carcinoma; HCV: Hepatitis C virus; HD: Hemodialysis; HIV: Human immunodeficiency virus; HLA: Human leukocyte antigen; HWE: Hardy-Weinberg equilibrium; LD: Linkage disequilibrium; MAF: Minor allele frequency; MHC: Major histocompatibility complex; miRNA: microRNA; mRNA: Messenger RNA; OR: Odds ratio; PBD: Paid blood donors; SLE: Systemic lupus erythematosus; SNP: Single nucleotide polymorphism; SVC: Spontaneous viral clearance; WHO: World Health Organization

\section{Acknowledgements}

Not applicable.

\section{Funding}

This study was supported by National Natural Science Foundation of China (Grant No. 81502853, 81473028, 81473029, 81773499, and 81703273), Natural Science Foundation of Jiangsu Province (No. BK20151026, and BK20171054), the Jiangsu Province Medical Young Talent (No.QNRC2016616), and the Science and Technology Development Fund Key Project of Nanjing Medical University (No. 2016NJMUZD012).

Availability of data and materials

All data generated or analysed during this study are included in this published article and its supplementary information files.

Authors' contributions

$\mathrm{PH}, \mathrm{YZ}$ and HF conceived and designed the experiments; HF, $\mathrm{TT}$ and JW performed the experiments; PH, YF and MY analyzed the data; JL, RY and XX contributed reagents/materials/analysis tools; $\mathrm{PH}, \mathrm{YL}, \mathrm{PL}$ and HF wrote the paper. All authors read and approved the final manuscript. 


\section{Ethics approval and consent to participate}

Each participates was recruited prior informed consent, agreed to participate in this study and sample collection. The study followed the Helsinki Declaration and was approved by the Institutional Review Board of Nanjing Medical University (Nanjing, China).

\section{Consent for publication}

Not applicable.

\section{Competing interests}

The authors declare that they have no competing interests.

\section{Publisher's Note}

Springer Nature remains neutral with regard to jurisdictional claims in published maps and institutional affiliations.

\section{Author details \\ 'Department of Epidemiology and Biostatistics, School of Public Health, Nanjing Medical University, Nanjing 211166, China. ${ }^{2}$ Institute of Epidemiology and Microbiology, Huadong Research Institute for Medicine and Biotechnics, Nanjing, China. ${ }^{3}$ Pubilc Health Sciences Department, Karolinska Institute, Solna, Sweden. ${ }^{4}$ Department of Infectious Diseases, the First Affiliated Hospital of Nanjing Medical University, Nanjing 210029, China. ${ }^{5}$ Faculty of Life Science and Technology, Kunming University of Science and Technology, Yunnan 650500, China. ${ }^{6}$ Department of Basic and Community Nursing, School of Nursing, Nanjing Medical University, Nanjing 211166 China.}

Received: 10 July 2017 Accepted: 20 November 2017

Published online: 06 December 2017

\section{References}

1. World Health Organization. Guidelines for the screening, care and treatment of persons with chronic hepatitis C infection Updated version. Geneva: World Health Organization; 2016.

2. Rehermann B, Nascimbeni M. Immunology of hepatitis B virus and hepatitis C virus infection. Nat Rev Immunol. 2005;5:215-29.

3. Sun J, Li K, Shata MT, Chan TS. The immunologic basis for hepatitis C infection. Curr Opin Gastroenterol. 2004;20:598-602.

4. Thomas DL, Astemborski J, Rai RM, Anania FA, Schaeffer M, Galai N, et al. The natural history of hepatitis $C$ virus infection: host, viral, and environmental factors. JAMA. 2000;284:450-6.

5. Amini M, Poustchi $H$, Hepatitis C. Virus spontaneous clearance: immunology and genetic variance. Viral Immunol. 2012;25:241-8.

6. Spaan $\mathrm{M}$, Janssen $\mathrm{HL}$, Boonstra A. Immunology of hepatitis $\mathrm{C}$ virus infections. Best Pract Res Clin Gastroenterol. 2012;26:391-400.

7. Elahi $\mathrm{S}$, Horton $\mathrm{H}$. Association of HLA-alleles with the immune regulation of chronic viral infections. Int J Biochem Cell Biol. 2012;44:1361-5.

8. Brown MA, Kennedy LG, Macgregor AJ, Darke C, Duncan E, Shatford JL, et al. Susceptibility to ankylosing spondylitis in twins the role of genes, HLA, and the environment. Arthritis \& Rheumatism. 1997;40:1823-8.

9. Watson AJ, DeMars R, Trowbridge IS, Bach FH. Detection of a novel human class II HLA antigen. Nature. 1983;304:358-61.

10. McKiernan S, Kelleher D. Immunogenetics of hepatitis C virus. J Viral Hepat 2000;7(Suppl 1):13-4.

11. Alric L, Izopet J, Fort M, Vinel JP, Fontenelle P, Orfila C, et al. Study of the association between major histocompatibility complex class II genes and the response to interferon alpha in patients with chronic hepatitis $C$ infection. Hum Immunol. 1999;60:516-23.

12. Singh R, Kaul R, Kaul A, Khan K. A comparative review of HLA associations with hepatitis B and C viral infections across global populations. World J Gastroenterol. 2007;13:1770-87.

13. Samimi-Rad K, Sadeghi F, Amirzargar A, Eshraghian MR, Alavian SM, Rahimnia R. Association of HLA class II alleles with hepatitis C virus clearance and persistence in thalassemia patients from Iran. J Med Virol. 2015;87:1565-72.

14. Kamatani Y, Wattanapokayakit S, Ochi H, Kawaguchi T, Takahashi A, Hosono $\mathrm{N}$, et al. A genome-wide association study identifies variants in the HLA-DP locus associated with chronic hepatitis B in Asians. Nat Genet. 2009;41:591-5.
15. Png E, Thalamuthu A, Ong RTH, Snippe H, Boland GJ, Seielstad M. A genome-wide association study of hepatitis $B$ vaccine response in an Indonesian population reveals multiple independent risk variants in the $\mathrm{HLA}$ region. Hum Mol Genet. 2011;20:3893-8.

16. Al-Qahtani AA, Al-Anazi MR, Abdo AA, Sanai FM, Al-Hamoudi W, Alswat KA, et al. Association between HLA variations and chronic hepatitis B virus infection in Saudi Arabian patients. PLoS One. 2014;9:e80445.

17. Zhang J, Zhan W, Yang B, Tian A, Chen L, Liao Y, et al. Genetic polymorphisms of rs3077 and rs9277535 in HLA-DP associated with systemic lupus erythematosus in a Chinese population. Sci Rep. 2017;7:39757.

18. Jiang J, Li N, Shen Y, Liu J, Liu L, Du J, et al. Genetic variants in HLA-DP/DQ contribute to risk of cervical cancer: a two-stage study in Chinese women. Gynecol Oncol. 2013;129:401-5.

19. Liu X, Yang B, Li L, Cai B, Liao Y, Li L, et al. Association of HLA-DP/DQ and STAT4 polymorphisms with ankylosing spondylitis in Southwest China. Int Immunopharmacol. 2016;39:10-5.

20. Morishima C, Polyak SJ, Ray R, Doherty MC, Di Bisceglie AM, Malet PF, et al. Hepatitis $C$ virus-specific immune responses and quasi-species variability at baseline are associated with nonresponse to antiviral therapy during advanced hepatitis C. J Infect Dis. 2006:193:931-40.

21. Bruno R, Sacchi P, Maiocchi L, Zocchetti C, Filice G. Host factors affecting the outcome of treatment of hepatitis C. Rev Gastroenterol Disord. 2004; 4(Suppl 1):S3-7.

22. Diaz G, Amicosante M, Jaraquemada D, Butler RH, Guillen MV, Sanchez M, et al. Functional analysis of HLA-DP polymorphism: a crucial role for DPbeta residues $9,11,35,55,56,69$ and 84-87 in T cell allorecognition and peptide binding. Int Immunol. 2003;15:565-76.

23. Lombard Z, Brune AE, Hoal EG, Babb C, Van Helden PD, Epplen JT, et al. HLA class II disease associations in southern Africa. Tissue Antigens. 2006;67:97-110.

24. De Re V, Caggiari L, Monti G, Libra M, Spina M, Dolcetti R, et al. HLA DR-DQ combination associated with the increased risk of developing human HCV positive non-Hodgkin's lymphoma is related to the type II mixed cryoglobulinemia. Tissue Antigens. 2010:75:127-35.

25. Yue M, Xu K, MP W, Han YP, Huang P, Peng ZH, et al. Human leukocyte antigen class II alleles are associated with hepatitis $C$ virus natural susceptibility in the Chinese population. Int J Mol Sci. 2015;16:16792-805.

26. Xu T, Sun M, Wang H. Relationship between HLA-DQ gene polymorphism and hepatitis B virus infection. Biomed Res Int. 2017;2017:9679843.

27. Li Y, Huang Q, Tang JT, Wei TT, Yan L, Yang ZQ, et al. Correlation of HLADP/DQ polymorphisms with transplant etiologies and prognosis in liver transplant recipients. Medicine (Baltimore). 2017:96:e7205.

28. El-Bendary M, Neamatallah M, Esmat G, Kamel E, Elalfy H, Besheer T, et al. Associations of human leucocyte antigen class II-DQB1 alleles with hepatitis $C$ virus infection in Egyptian population: a multicentre family-based study. J Viral Hepat. 2016;23:961-70.

29. Walker CM. Adaptive immunity to the hepatitis C virus. Adv Virus Res. 2010; 78:43-86

30. Thimme R, Binder M, Bartenschlager R. Failure of innate and adaptive immune responses in controlling hepatitis $C$ virus infection. FEMS Microbiol Rev. 2012;36:663-83.

31. Gauthiez E, Habfast-Robertson I, Rueger S, Kutalik Z, Aubert V, Berg T, et al. A systematic review and meta-analysis of HCV clearance. Liver Int. 2017;37: 1431-45.

32. Wasityastuti $W$, Yano $Y$, Ratnasari N, Triyono T, Triwikatmani C, Indrarti F, et al. Protective effects of HLA-DPA1/DPB1 variants against hepatitis $B$ virus infection in an Indonesian population. Infect Genet Evol. 2016;41:177-84.

33. Bartel DP. MicroRNAs: target recognition and regulatory functions. Cell. 2009;136:215-33.

34. Martin P. Friedman LS. Chronic viral hepatitis and the management of chronic renal failure. Kidney Int. 1995;47:1231-41.

35. Fabrizi F, Martin P. Hepatitis B. Virus infection in dialysis patients. Am J Nephrol. 2000;20:1-11

36. Huang CC. Hepatitis in patients with end-stage renal disease. J Gastroenterol Hepatol. 1997;12:S236-41.

37. Hu L, Zhai X, Liu J, Chu M, Pan S, Jiang J, et al. Genetic variants in human leukocyte antigen/DP-DQ influence both hepatitis B virus clearance and hepatocellular carcinoma development. Hepatology. 2012;55:1426-31. 